\title{
Addressing Health System's Leadership Challenges through Different Problem-Solving Approaches
}

\author{
Tecla Chelagat \\ Strathmore University Business School \\ Gilbert Kokwaro \\ Strathmore University Business School \\ Jim Rice \\ Strathmore University Business School \\ Joseph Onyango \\ Strathmore University Business School
}

Kenya continues to face significant challenges in providing basic health services for all despite the devolution of health system functions. Some of these challenges have been attributed to healthcare leaders that are ill-equipped to succeed in their roles. This calls for innovative health worker training that yields impact. The purpose of this study was to describe health system leadership challenges in 19 counties in Kenya and how the challenges have been addressed. The research design is longitudinal without a random assignment. Comparison of catalyst projects' key health system performance indicators for baseline, endline, and post-training indicated positive results ( $p=0.0018$ and 0.7655$)$ respectively.

\section{INTRODUCTION}

Despite the significant investment of about $\$ 8$ trillion in global health care spending, millions of people still die each year from preventable causes (Thomas \& Wise, 2016). This has been attributed among other factors that a majority of the people responsible for leading, managing and governing healthcare have little or no preparation to succeed in this role (MSH, 2012). Leadership and governance is one of the health system building blocks and is now recognized as an important determinant of strengthening national health systems and, at the core of achieving the health-related goals(Dodd \& Cassels, 2006; United Nations, 2014). Leadership is an enabler of governance, management, service delivery, and community engagement; in that when people consistently practice leadership, will ultimately result to improved service delivery hence a healthier population (Rice, 2014; English \& Todd, 2011; Nzinga, Mbaabu, \& English, 2013).

In 2010, Kenya's new constitution created a devolved system of government with 47 counties. Health service delivery was devolved to the counties in 2013. So far health system performance in Kenya 
remains poor (Obare, Brolan, \& Hill, 2014). Most of these challenges are a result of the devolution of health service provision (Regmi, 2014). Devolution was meant to be the vehicle towards the attainment of the World Health Organizations' defined Millennium development Goals number three, four, five and six; the Sustainable Development Goal number three (health) and the social pillar (health) for vision 2030 (United Nations, 2014). However, devolution reforms are highly complex and challenging to implement (Bossert \& Beauvais, 2002; Regmi, 2014). As a result, the devolution in Kenya has brought with it several challenges with regard to health service provision due to radical departure from the highly centralized form of governance system, leading to weak, unresponsive, inefficient, and inequitable distribution of health services in the country (Barker, Mulaki, Mwai, \& Dutta, 2014; Kimathi, 2017). This was further aggravated by the lack of preparation of county governments to adopt and deliver health services. Additionally, they inherited a malfunctioning system characterized by poor leadership, low capacity to respond to changes and high disparities in rural versus urban infrastructure (Ndavi, Ogola, Kizito, \& Johnson, 2009). Other pre-existing health system challenges included significant health worker shortage and low government budget spending on health estimated at $6 \%$ of government expenditure significantly below the Abuja Declaration commitment of 15\% (Adieno, Rono, \& Ibrahim, 2015). These identified health system challenges, however, can be addressed through appropriate leadership training of healthcare workers(WHO, 2010). Recently Examples, where such leadership development program (LDP) training has been shown to result in improved health system performance, are provided in the cases reviewed Peterson et al (2011); Hatt et al (2015) and coaching interventions cases reviewed by Theeboom \& Passmore (2015).

\section{Intervention Program}

\section{Leading High-performing Healthcare Organization Program (LeHHO)}

LeHHO program is a 9-month leadership development training of the Institute of Healthcare Management at Strathmore University Business School. The program was developed and implemented in partnership with Management Sciences for Health (MSH) under funding support by the United States Agency for International Development (USAID) between the years 2011-2016. The program was designed to enable senior national and county management teams address the most important health system challenges in a devolved system of government. A consortium of knowledge partners and Ministry of Health conducted a training needs assessment and then planned and designed a leadership program aimed at addressing the identified priority needs of the health sectors. The program cohort cycle is implemented within a 9-month period and composed of; 5 workshop modules; 4 team coaching sessions and 1 cross-learning site visit. The coaching session acts as a link between (a) the classroom learning; (b) the application of the learned knowledge in the workplace; and (c) through the implementation of team's priority projects using the leadership, management, and governance practices. Highly experienced local and international faculty and coaches were seconded to deliver the training.

In-line with the needs of the participants who are experienced managers, the primary focus of delivery was "participant-centered learning". This type of learning is particularly suitable for the target audience in that it has as its core ingredient that combines experiences through team participation. The teaching methodology included: case method, experiential learning, and group work. One of the key programs' anticipated outcomes is that at end of the program, the participants are expected to have prioritized and implemented a challenging project within their institutions through team coaching conversation using the challenge Model. Project sustainability was a major component of LeHHO program. The challenge model approach was intended to foster positive knowledge transfer at work environment during and post-training. While the successes of programs were documented during and at the end of the training as success stories, evaluation, and documentation of impact and sustainability of the projects positive results were overlooked.

\section{Theoretical Conceptual Framework}

The current study is guided by the theory of change framework adopted from the Management Sciences for Health "integrated leadership management and governance results framework". The 
framework integrates leading, managing and governance practices approach towards developing managers who lead and govern well. The program is anchored on the assumption that leadership can be learned through action learning approach where participants learn to apply a set of leading, managing and practices to address their real workplace challenges over time (Dwyer, Paskavitz, Vriesendorp, \& Johnson, 2006). Whereas traditional leadership programs often physically and psychologically separate the participant from his or her work environment, the LMG approach operates on a framework which connects the training to current challenges facing participants in their workplaces and with results through the implementation of action plans. The results model (figure 1) illustrates the program principle that measurement of leadership, management and governance capacity is not an end itself; rather, working on leadership, management and governance skills is a means of improving work climate, management and governance system, and eventually strengthening health services (LeMay \& Ellis, 2008). The study, therefore, focused on evaluating results on outcome and sustainability level with an aim to determine contribution rather than demonstrate causality.

\section{FIGURE 1 \\ THEORETICAL CONCEPTUAL FRAMEWORK}

\section{Conceptual Model: Leading, Managing and Governing for Results}
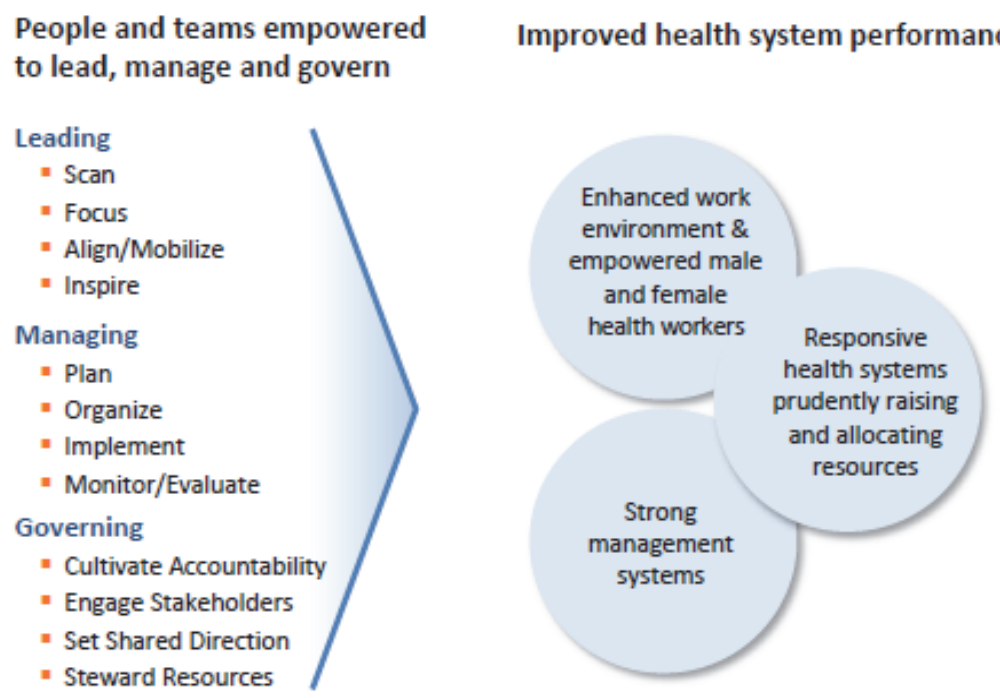

Results

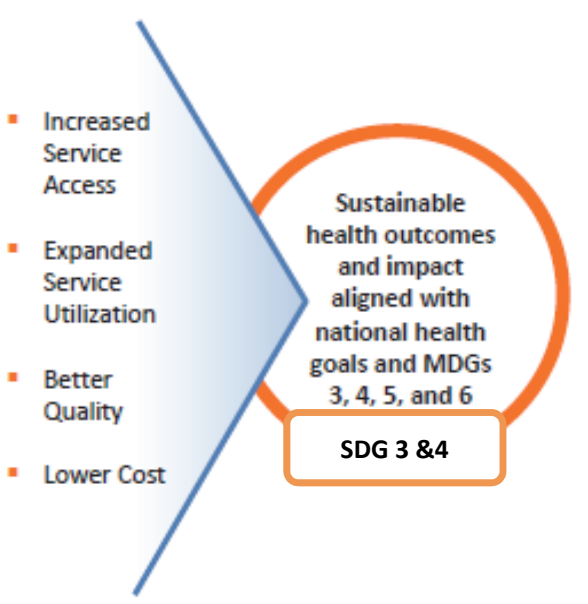

Source: The Leading, Managing and Governing Results Framework, (Management Sciences for Health, 2008).

\section{The Challenge Model}

The Challenge Model (MSH, 2008) is a systematic approach to planning and problem solving that program participants use to apply to a real worksite problem. The purpose of using the Challenge Model was to identify priority institutional improvements projects. These projects were aligned to institutional strategic plans. It is these projects that provided a platform for coaching. The model relies on the principle that measurement of leadership, management and governance capacity is not an end itself, but rather that the application of defined practices to achieve a desired measurable result is a means of improving work climate, management and governance system, and strengthening health service delivery. The Challenge Model has eight critical systematic steps: (i) review your organizational mission and strategic priorities; (ii) creation of a shared vision, (iii) agreement on one measurable result; (iv) assessment of the current situation; (v) identification of obstacles and their root causes; (vi) definition of key challenge and select priority actions; (vii) development of an action plan; and (viii) implementation of 
action plan and monitor and evaluate your progress. Participants learn together about the power of teams; the complementarity and integration of each other's skills; and the practice of reflecting on their own behavior as it impacts others, including both clients and colleagues. Unique among other leadership improvement approaches, the Strathmore leadership program integrates the conscious, systematic application of leading and managing to lasting attitudinal changes as participants pass on their new skills and enthusiasm to others. The coaching sessions were underpinned by a cognitive-behavioral, solutionfocused framework (Grant, Curtayne, \& Burton, 2009). This coaching approach enables the coach and teams to achieve their set goals by systematically following the Challenge Model critical steps to address the team's priority challenges. The role of a coach is to help teams set a goal, develop actionable plans and monitor and evaluate their project implementation progress between the coaching sessions throughout the 9 months training period.

FIGURE 2

\section{THE CHALLENGE MODEL}

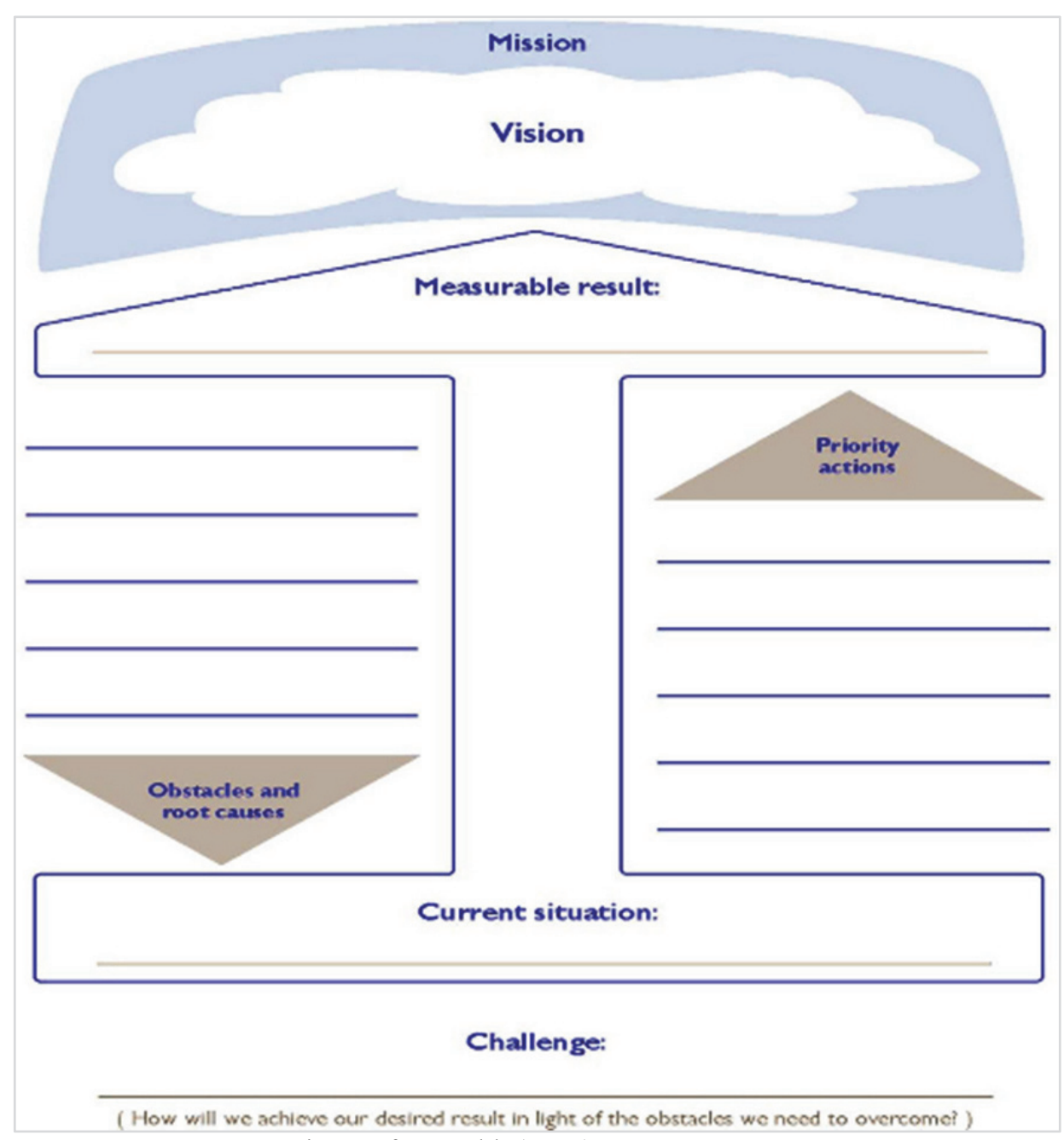

Source: Management Sciences for Health (2008)

\section{Coaching Using the Challenge Model}

Coaching is defined as a process of supporting coaches to step back, and take in the "big picture," and craft a future they desire through a commitment to the goal (Rosinski, 2003). Coaching and mentoring are popular capacity building tools, especially in the area of leadership development as a method of 
enhancing performance and a leadership style that gets results (Brown \& Grant, 2010; Goleman, Boyatzis, \& McKee, 2002; Grant, 1996). According to Management Sciences for Health (2008), an organization's failure to achieve its objective can sometimes be traced to unclear objectives or mismatch between what people set out to do and what they actually accomplish leading to resource wastage and frustration. Coaching managers have been proposed to influence results through a coaching conversation and the challenge model offers a systematic approach on how to structure the coaching conversation towards achieving an agreed desired goal. The LMG framework utilized in the LeHHO program was designed to help teams achieve superior performance. Coaches are therefore tasked with the responsibility to help leaders grow notably by demonstrating their own leadership skills through practice. Part of the growth is leaders' ability to act as coaches after completing their six-month project-based team coaching process. More fundamentally the trained leaders-coaches post-training are tasked to transfer the learnt knowledge to their teams back in their organisations to find practical solutions to the concrete challenges they face by planning well, improving leadership and communication, achieve ambitious work goals, have a better life balance, understand and use emotions, develop their creative thinking, overcome harmful stress and establish constructive relationships.

A study by Seims (Seims et al., 2012) on strengthening management and leadership practices to increase health-service delivery in Kenya is the only study undertaken so far on the impact of leadership development training on health system performance. The researchers used quasi-experimental design with comparison groups but without random assignment to analyze 67 projects teams of DHMT from 6 provinces in Kenya. The study findings positively revealed the positive impact of leadership training whereby the health service delivery indicators increased from $54 \%$ at baseline to $65 \%$ at endline, and $67 \%$ post-intervention, as compared with a control group and that the improvements were sustained at least for six years (Seims et al. 2012). An evidence-based study by West and others on leadership and leadership development in healthcare concludes that the challenges that face health care organizations are too great and too many for leadership to be left to chance or piecemeal approaches (West et al., 2015). The finding on the empirical reviews on impact of leadership on health system performance confirms that: (i) strengthening the leadership and management skills of health teams, through team-based approaches focused on selected challenges, and contributes to improved health service delivery outcomes; and (ii) coaching is an effective intervention in organizations towards increased goal attainment, enhanced solution-focused thinking, a greater ability to deal with change, increased leadership self-efficacy and resilience, and decrease in depression. However, it is important to mention that only one leadership study was done in Kenya pre-devolution by Seims et al. (2012), while for the coaching studies none was from Africa especially in a healthcare training context.

\section{STUDY DESIGN}

The study adopted a longitudinal design using priority project selected baseline, endline, and posttraining indicators; to empirically estimate the attributed impact of an intervention on health system performance indicators and without a random assignment. The target population comprised of senior healthcare management teams drawn from 19 counties in Kenya and trained in Strathmore leadership training (LeHHO. The participants were from the public, private, faith-based and non-governmental health institutions. The LeHHO program has trained a total of 165 county health leaders from 19 counties between the years (2010-2016). The leaders were trained to acquire and practice leadership knowledge, skills and practices at the work environment during and post-training. During the training, 165 participants clustered themselves into 69 project-based teams, which they identified and committed to implementing an institutional improvement project as a catalyst towards improving the health system performance as informed by their county or institutional strategic plans. 39 team-based projects were followed up and data from priority projects indicators recorded and compared. 


\section{Data Collection Methods}

The study utilized both primary and secondary data. Primary data was collected using a questionnaire. The questionnaires comprised of closed-ended questions aimed at providing structured responses to the study's outcomes. A total of 39 study respondents for the project-based team leaders were interviewed. In order to enhance the validity and accuracy of data, the questionnaires were piloted within 2 counties on 4 selected team-based projects for feedback. The secondary data sources included program brochure, success stories publications, annual reports, and Strathmore University Business School and Management Sciences for Health website documents. The data provided background information on the participants and the program module evaluation status.

\section{Data Sources}

\section{Quantitative Methods}

Survey Process: A non-random sample of $(n=39)$ team leaders were called to be informed about the survey and informed consent was sent to them before sending the Google sheets link and complete the survey questions. The survey was piloted with 4 team members and it was estimated that it would take 12 minutes to complete the questionnaire. The questionnaire questions were drawn from the LMG and challenge model framework. The questions focused on the priority leadership challenge, implementation status of leadership practices on the challenge, team coaching focusing on the challenge and the results from the prioritized projects. The sampling unit was the institutional project and the sample respondents were the team leaders representing each project teams. We specifically focused on the experience of implementation of teams' institutional improvement project, which consequently presented opportunities for immediate knowledge application and link class with the work environment. The unit of study in this research was the project group team leader. Data were collected in 19 counties in Kenya between August and November 2018. Only 64\% of the team leaders filled the Google sheets in August 2018. A follow-up survey prompt was sent to non-respondents approximately two weeks later by mailing a postage response envelope with hardcopy questionnaire. All the 14 surveys were returned within time, resulting in $(\mathrm{n}=39)$ $100 \%$ response rate.

\section{Data Analysis}

The completed questionnaires were first edited for completeness and consistency then captured electronically and the quantitative information collected will be entered into SPSS 20. A two steps statistical analysis was performed using (i) descriptive statistics analysis, (ii) linear regression and t-test and (iii) impact were calculated using means and mean differences. Descriptive statistics analysis such as means, standard deviations and frequencies were derived from the baseline, endline and posttest measure of the priority project indicators for the treatment.

\section{Ethical Approval}

Ethical approval to conduct this study was obtained from the Strathmore University ethical review committees and the permit to conduct a study in the counties was obtained from the National Commission for Science, Technology, and Innovation (NACOSTI). The leadership knowledge transfer data were not considered as personal data as per NACOSTI and Strathmore University Ethics Review Committee approval since the study did not involve human biological material. The study participants were informed about voluntary participation. Names and identities of respondents were kept confidential, and any printed research materials were kept in a locked room within the health facilities. Participants were requested to sign informed consent allowing the use of photographs of before and after the project implementation where applicable. 


\section{RESULTS}

The study results are presented in four sub-sections: LeHHO team leader's demographics, health system pillars, baseline; endline; post-intervention indicator means for the priority projects and leadership development attributed tangible outcome.

\section{Demographic Characteristics of Participants}

For key informant closed-ended questionnaire and interviews, a total of 39 respondents filled the questionnaires and participated in the in-depth interviews. Table 1 depicts that there are $59 \%$ female and $41 \%$ male participated in the study. Nearly half (49\%) of the participants were between the age category of $46-55$ years. A total of $59 \%$ of the participants had a master's degree. This shows that the majority of participants have attained a reasonably high level of tertiary education. This is a reflection of Kenya's healthcare manager's recruitment and promotion practices are based on attainment of higher educational qualifications.

\section{TABLE 1 \\ PARTICIPANTS DEMOGRAPHICS INFORMATION}

\begin{tabular}{|c|c|c|c|}
\hline Item & Category & $\begin{array}{l}\text { Frequency } \\
\text { (No) }\end{array}$ & $\begin{array}{c}\text { Percentage } \\
(\%)\end{array}$ \\
\hline \multirow[t]{2}{*}{ Sex } & Male & 16 & $41 \%$ \\
\hline & Female & 23 & $59 \%$ \\
\hline \multirow[t]{4}{*}{ Age Category } & $26-35 y r s$ & 1 & $10 \%$ \\
\hline & 36- 45yrs. & 13 & $33 \%$ \\
\hline & $46-55 y r s$ & 19 & $49 \%$ \\
\hline & $>55 \mathrm{yrs}$ & 3 & $8 \%$ \\
\hline \multirow{4}{*}{$\begin{array}{l}\text { Highest } \\
\text { Education Level }\end{array}$} & Bachelor degree & 12 & $31 \%$ \\
\hline & Master degree & 23 & $59 \%$ \\
\hline & Doctoral degree & 1 & $3 \%$ \\
\hline & Others & 3 & $8 \%$ \\
\hline
\end{tabular}

\section{Health Sector Representation}

A total of 39 team-based projects were purposively selected. A sum of ( $n=23) 59 \%$ was from public sector teams, $(n=10) 26 \%$ were from the faith-based and NGO sector, and $(n=6) 15 \%$ were from the private sector.

\section{Scan of Priority Leadership Challenges Addressed by Healthcare Leaders}

The 39 team-based projects were clustered according to the WHO health system building blocks (WHO, 2010). Quality service delivery was the leading challenge across all the sectors at $43.6 \%$, Health information constituted $20.5 \%$ of the projects, leadership, and governance $15.4 \%$, human resources $10.3 \%$, medical products $7.7 \%$ and health finance $2.6 \%$. The projects are summarized in (figure 1 ) 
FIGURE 1

PRIORITY PROJECTS ALIGNED TO THE WHO HEALTH SYSTEM PILLARS

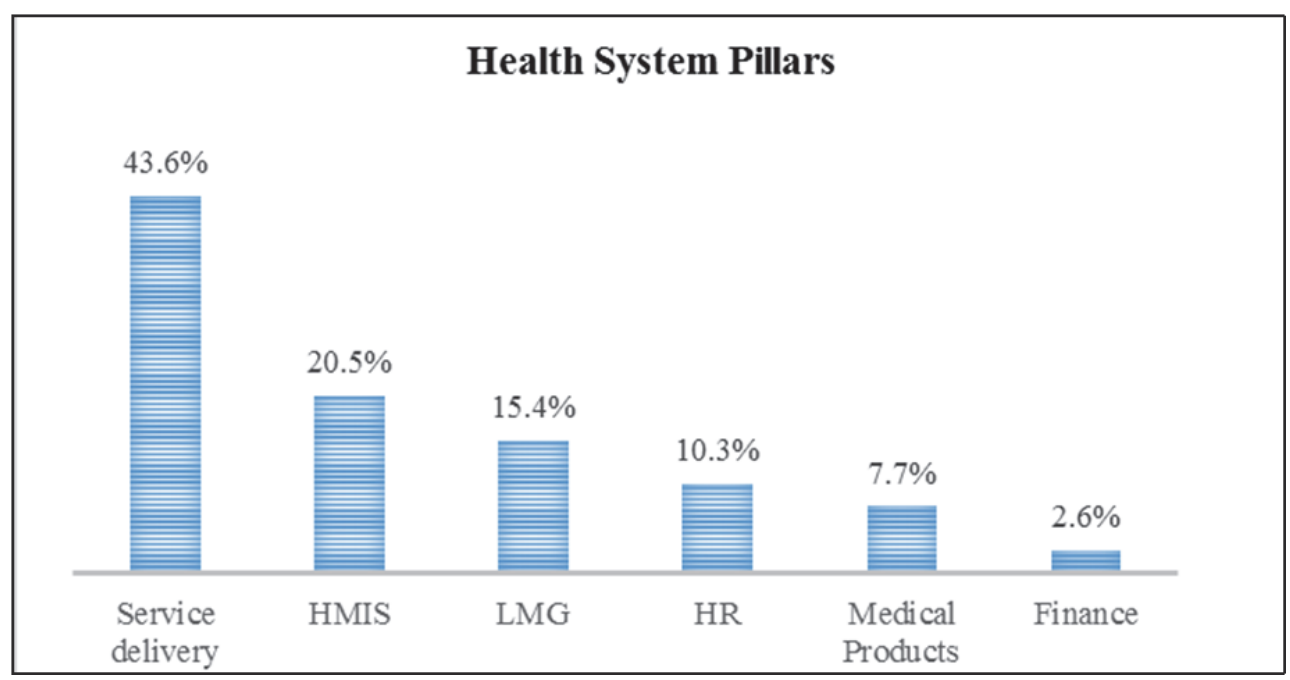

\section{Implementation Status of the Team-based Priority Challenge Projects}

A total of $(n=39)$ projects were prioritized by the teams as aligned to their strategic plan, and $(n=33)$ $85 \%$ of the prioritized projects achieved the desired measurable results (DMR) by the end of the training ( 9 th month). A total of $(\mathrm{n}=29) 88 \%$ of the implemented were sustained post-training. The trend of means from baseline, endline and post-intervention measures for the 39 projects were $(38,93.4 \& 87.7)$ respectively and are summarized in (figure 2).

FIGURE 3

MEANS FOR BASELINE, ENDLINE AND POSTLINE INDICATORS

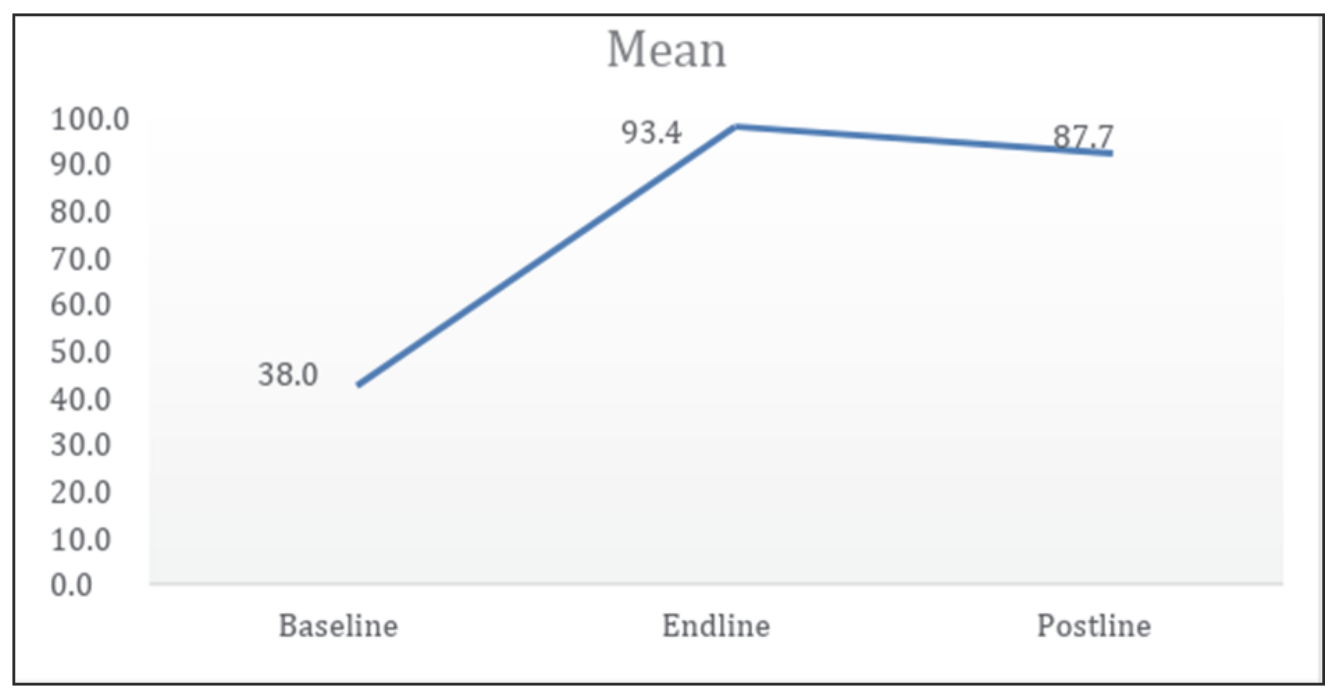

Effectiveness of the Application of Leadership Skills and Practices Through the Implementation of Priority Catalyst Projects

It was hypothesized that application of leadership, management and governance practices through priority challenges projects have a positive effect on health system performance. This is possible through the achievement of Desired Measurable Result (DMR) and priority project goal attainment. Data were 
analyzed using paired-sample t-tests. A significance level of .05 was set for the tests. Paired t-tests comparing baseline and endline revealed that participation in the LMG program was associated with significant increases in priority project goal attainment $\mathrm{P}=0.00186$. The $\mathrm{p}$-value for endline and postintervention was at $\mathrm{P}=0.76557$ thus not statistically significant as presented in the (table 2 ).

TABLE 2

The TEST OF TWO SAMPLE ASSUMING UNEQUAL VARIANCES

\begin{tabular}{lrrr}
\hline & Baseline & Endline & Postline \\
\hline Mean & 37.98649 & 93.44595 & 87.67567568 \\
Variance & 4487.09 & 6393.497 & 7359.114114 \\
Observations & 37 & 37 & 37 \\
Hypothesized Mean Difference & 0 & & 0 \\
Df & 70 & & 72 \\
$\mathrm{t} \mathrm{Stat}$ & -3.23408 & & 0.299298428 \\
$\mathrm{P}(\mathrm{T}<=\mathrm{t})$ one-tail & 0.000932 & & 0.382787307 \\
$\mathrm{t}$ Critical one-tail & 1.666914 & & 1.666293696 \\
$\mathrm{P}(\mathrm{T}<=\mathrm{t})$ two-tail & $\mathbf{0 . 0 0 1 8 6 4}$ & & $\mathbf{0 . 7 6 5 5 7 4 6 1 4}$ \\
$\mathrm{t}$ Critical two-tail & 1.994437 & & 1.993463567 \\
\hline
\end{tabular}

\section{DISCUSSION}

Leadership is considered essential in any organization because it involves defining direction, communicating vision, inspiring the heart and empowering teams towards achieving organizational success (Mansour, Mansour, \& El Swesy, 2010). However, while the leadership is deemed essential for healthcare leaders, significant effort and investments should go into the application of leadership and governance practices to real workplace challenges. The study findings bring together a series of integrated evidence-based approaches for enhancing the transfer of leadership practices learned in a classroom to the real workplace setting. This is made possible through the identification and implementation of priority challenges (catalyst projects) through team-based coaching and challenge model approach. The findings show that service delivery and human resources for health are the key healthcare leadership challenges across all sectors. Even though projects did not focus on human resources because it was outside their sphere of influence few institutions were determined to implement human resources projects and half of them were unsuccessful. Findings also demonstrate that the achievement of priority project goals is highly attributed to the integration of both teaching and application of learned practices which ultimately results in the improvement of the health systems performance indicators. The LMG programs, therefore, act as a catalyst for strengthening health systems performance towards achievement of the health goals in a resource-scarce setting through prioritization.

\section{CONCLUSION}

Evidently, the only way to achieve the devolved health system objective is through evidenced-based health system intervention. Without the evidence, it is more difficult to scale-up best practices. The results of the study will be useful in formulating relevant policies to guide future training activities in Leadership and Governance to improve health system performance. 


\section{LIMITATION}

The following were the limitations of the methodology adopted in this study: The Strathmore healthcare leadership program was the exclusive point of the data source. This limits the results to the program alumni. Given that it a longitudinal study, the quality of information may not represent the current state of institutional leadership due to change in leadership positions and transfers. However, follow-up call and emails were sent to alumni who left the institutions to confirm the team results.

\section{ACKNOWLEDGEMENT}

We are grateful to all the Health Managers and their facility teams from all participating Counties in Kenya for sharing their experiences and access to their projects and data.

CT was the principal investigator who conceptualized, designed, implemented, analyzed and interpreted the data. KG contributed in the literature review, interpretation of results and review of the paper, OJ \& RJ made a significant contribution by providing advice on design, literature reviews, reviewed and suggested modification of drafts and approval of the final manuscript. The first author (CT) led in writing the manuscript and reviewed it based on comments from the other authors. All the authors reviewed and approved the submission of the final manuscript.

\section{ENDNOTES}

1. Abbreviations. LMG: Leadership, Management and Governance; LEHHO: Leading High-Performing Organisations; HSS: Health System Strengthening; HS: Health Services; LDP: Leadership Development Program; DMR: Desired Measurable Result; SBS Strathmore Business School; USAID: US Agency for International Development, MSH: Management Sciences for Health; SPSS: Statistical Package for Social Scientists.

2. Ethical approval. Ethical approval to conduct this study was obtained from the Strathmore University ethical review committees (Protocol ID No. SU-IRB 0243/18) and the permit to conduct the study in the counties was obtained from the National Commission for Science, Technology and Innovation (NACOSTI/P/18/21001/23609).

3. Additional File 1: Semi structured questionnaire

Additional File 3: Ethical approval permit

4. Availability of data and material. The data utilized for this study are both quantitative original data can be made available from the first author upon reasonable request. 


\section{REFERENCES}

Adieno, D., Rono, \& Ibrahim, M. (2015). Impact of devolution on health service delivery in Kenya: county roundtable forums. Impact of Devolution on Health Service Delivery in Kenya: County Roundtable Forums. Retrieved from http://devinit.org/post/impact-of-devolution-on-healthservice-delivery-in-kenya-county-roundtable-forums/

Barker, C., Mulaki, A., Mwai, D., \& Dutta, A. (2014). Devolution of Healthcare in Kenya. Assessing County Health System Readiness in Kenya : A review of selectd Health Inputs.

Bossert, T., \& Beauvais, J. (2002). Decentralization of health systems in Ghana, Zambia, Uganda and the Philippines: a comparative analysis of decision space. Health Policy and Planning, 17(1), 14-31.

Brown, S., \& Grant, A. (2010). From GROW to GROUP: theoretical issues and a practical model for group coaching in organisations. Coaching: An International Journal of Theory, Research and Practice, 2(1).

Dodd, R., \& Cassels, A. (2006). Health, development and the Millennium Development Goals. Annals of Tropical Medicine \& Parasitology, 100(5-6), 379-387. https://doi.org/10.1179/136485906x97471

Dwyer, J., Paskavitz, M., Vriesendorp, S., \& Johnson, S. (2006). An urgent call to professionalize leadership and management in health care worldwide. Boston, MA: Management Sciences for Health. Retrieved from http://pdf.usaid.gov/pdf_docs/PNADI689.pdf

English, M., \& Todd, J. (2011). Assessing health system interventions : key points when considering the value of randomization. (April), 907-912. https://doi.org/10.2471/BLT.11.089524

Goleman, D., Boyatzis, R. E., \& McKee, A. (2002). The New Leaders - Transform the Art of Leadership into the Science of Results. Time-Werner.

Grant, A., Curtayne, L., \& Burton, G. (2009). Executive coaching enhances goal attainment, resilience and workplace well-being: a randomised controlled study. The Journal of Positive Psychology, $4(5)$.

Grant, R. M. (1996). Toward a knowledge-based view (KBV) theory. Strategic Management Journal, 17(Winter), 109-122. https://doi.org/10.1002/smj.4250171110

Hatt, L., Johns, B., Connor, C., Meline, M., Kulka, M., \& Moat, K. (2015). Impact of Health-Systems Strengthening on Health. United States Agency for International Development (USAID). Retrieved from https://www.hfgproject.org/wp-content/uploads/2016/03/Impact-ofHealthSystems-Strengthening-on-Health-7-24-1.pdf

Health, M. S. for. (2008). Leadership Can Be Learned, But How Is It Measured? -. Retrieved from http://projects.msh.org/Documents/OccasionalPapers/upload/How_Can_Leadership_Be_Measure dOP.pdf

Health, M. S. for. (2012). Designing and implementing training programs: Human Resources Management. Retrieved from https://www.msh.org/sites/msh.org/files/mds3-ch52-trainingmar2012.pdf

Kimathi, L. (2017). Challenges of the Devolved Health Sector in Kenya : Teething Problems or Systemic Contradictions? XLII(1), 55-77.

LeMay, N., \& Ellis, A. (2008). Leadership Can Be Learned, But How Is It Measured? Management Sciences for Health, 8(8), 1-29. Retrieved from https://www.msh.org/sites/msh.org/files/how_can_leadership_be_measured.pdf

Mansour, M., Mansour, J. B., \& El Swesy, A. H. (2010). Scaling up proven public health interventions through a locally owned and sustained leadership development programme in rural Upper Egypt. Human Resources for Health, 8(1), 1. Retrieved from https://human-resourceshealth.biomedcentral.com/articles/10.1186/1478-4491-8-1

Ndavi, P. M., Ogola, S., Kizito, P. M., \& Johnson, K. (2009). Decentralizing Kenya's Health Management System: An Evaluation. Calverton, Maryland, USA:: Macro International Inc. Retrieved from http://www.dhsprogram.com/pubs/pdf/WPK1/WPK1.pdf 
Nzinga, J., Mbaabu, L., \& English, M. (2013). Service delivery in Kenyan district hospitals - what can we learn from literature on mid-level managers? Human Resources for Health, 11(1), 1. https://doi.org/10.1186/1478-4491-11-10

Obare, V., Brolan, C. E., \& Hill, P. S. (2014). Indicators for Universal Health Coverage: can Kenya comply with the proposed post-2015 monitoring recommendations? International Journal for Equity in Health, 13(1). https://doi.org/10.1186/s12939-014-0123-1

Peterson, E. A., Dwyer, J., Howze-Shiplett, M., Davison, C., Wilson, K., \& Noykhovich, E. (2011). Presence of Leadership and Management in Global Health Programs: Compendium of Case Studies. The George Washington University: Washington DC.

Regmi, K. (2014). Decentralizing Health Services: A Global Perspective. New York: Springer.

Rosinski, P. (2003). Coaching Across Cultures: New Tools for Leveraging National, Corporate and Professional Differences. London: Nicholas Brealey Publishing.

Seims, L. R. K., Alegre, J. C., Murei, L., Bragar, J., Thatte, N., Kibunga, P., \& Cheburet, S. (2012). Strengthening management and leadership practices to increase health-service delivery in Kenya: an evidence-based approach. Human Resources for Health, 10, 25. https://doi.org/10.1186/14784491-10-25

Theeboom, T., \& Passmore. (2015). Coaching Psychology: A Journey of Development on Research. Coaching Psychology: Meta theoretical Perspectives and Applications in Multicultural Contexts. New York. Springer.

Thomas, J., \& Wise, S. (2016). Global Health Care Outlook. Carlyle Group.

United Nations, S. D. S. N. (2014). Health in the Framework of Sustainable Development. Retrieved from http://unsdsn.org/wp-content/uploads/2014/02/Health-For-All-Report.pdf

West, M., Armit, K., Loewenthal, L., Eckert, R., West, T., \& Lee, A. (2015). Leadership and Leadership Development in Health Care: The Evidence Base. Retrieved from http://www.kingsfund.org.uk/sites/files/kf/field/field_publication_file/leadership-leadershipdevelopment-health-care-feb-2015.pd

WHO. (2010). E everybody's Business Strengthening Health Systems to Improve Health Outcomes WHON Framework Action, 3. https://doi.org/10.1371/journal.pone.0013372 